\title{
Sistem Pendukung Keputusan Pemilihan Rumah Kostt Di Sekitar Lingkungan Kampus Universitas Serang Raya Menggunakan Metode Analytical Hierarchy Process (AHP)
}

\author{
Harsiti $^{1}$, Rinny Lestari ${ }^{2}$, Endah Kurniawati ${ }^{3}$, Muhar Dizani ${ }^{4}$ \\ Program Studi Sistem Informasi, Fakultas Teknologi Informasi Universitas Serang Raya \\ Jl. Raya Cilegon - Serang Km.5 Taman Drangong Kota serang - Banten, indonesia \\ ${ }^{1}$ harsiti@yahoo.com, ${ }^{2}$ rinnylestaril5@gmail.com, ${ }^{3}$ iyulistiani46@gmail.com, ${ }^{4}$ zanimuhardi@gmail.com
}

\begin{abstract}
Menentukan rumah kost sering menjadi kesulitan bagi mahasiswa pendatang karena lokasi kampus yang jauh dari rumah membuat mahasiswa kurang mengetahui tentang rumah kost yang pantas dan layak untuk ditinggali. Sering terjadinya ketidakcocokan antara mahasiswa dengan rumah kost yang mereka pilih mengakibatkan mahasiswa sering berpindahpindah yang tentunya dapat menelan banyak waktu dan biaya. Untuk meminimumkan kendala tersebut diperlukan suatu sistem pendukung keputusan untuk menganalisa rumah kost yang sesuai dengan kebutuhan mahasiswa. Pada penelitian ini dibahas mengenai penerapan metode AHP. Data diperoleh dari survey yang dilakukan terhadap rumah kost di sekitar kampus. Sistem pendukung keputusan dalam pemilihan rumah kost dilakukan berdasarkan 4 kriteria yaitu harga, jarak dengan kampus, kontur bangunan serta ukuran. Hasil dari penelitian adalah sebuah analisis proses seleksi berupa nilai akhir rumah kostt sebagai rekomendasi bagi pengambil keputusan untuk memilih rumah kost yang cocok serta sesuai seperti yang diinginkan oleh mahasiswa.
\end{abstract}

Kata kunci:Sistem Pendukung Keputusan, AHP, Rumah Kost.

\section{LATAR BELAKANG}

Pembuat keputusan kerap kali dihadapkan pada kerumitan dan lingkup pengambilan keputusan dengan data yang begitu banyak. Untuk kepentingan itu sebagian besar dengan mempertimbangkan risiko manfaat / biaya, dihadapkan pada suatu keharusan mengandalkan seperangkat system yang mampu memecahkan masalah secara efisien dan efektif yang kemudian disebut Sistem Pendukung Keputusan (Simarmata, 2006).

Universitas Serang Raya (UNSERA) merupakan Pergutuan Tinggi swasta terkemuka di Provinssi Banten, yang memiliki letak yang sangat strategis . Hal ini mengakibatkan meningkatnya minat masyarakat untuk melanjutkan studi di UNSERA, hingga saat ini jumlah mahasiswanya pun selalu meningkat setiap tahunnya baik yang berasal dari dari dalam dan luar provinsi. Oleh karena itu, hal ini membuka peluang bagi pelaku usaha/bisnis untuk membuka usaha rumah kostt yang diharapkan dapat menjadi sumber penghasilan bagi masyarakat setempat. Banyaknya rumah kostt yang berada di sekitar kampus membuat mahasiswa merasa bingung dalam proses pemilihan rumah kostt.Tak jarang ketidakcocokan rumah kostt yang dipilih membuat mahasiswa sering berpindah-pindah rumah kostt, hal ini mengakibatkan ketidakefektifan dalam hal biaya, waktu dan tenaga. Mencari rumah kostt bagi mahasiswa yang berasal dari luar daerah bukan lah hal mudah, mengingat mahasiswa tersebut belum mengenal lokasi, khususnya lokasi di sekitar kampus. Jarak dari kampus, harga, fasilitas, keadaan lingkungan sekitar menjadi pertimbangan tersendiri bagi mahasiswa. Hal ini dapat mempengaruhi keputusan mahasiswa dalam menentukan rumah kostt yang tepat untuk ditempati. Oleh karna itu, untuk memberikan solusi terbaik dalam proses pemilihan rumah kostt yang tepat yaitu dengan menerapkan metode AHP.

\section{DASAR TEORI}

\section{A. Decision Support System (DSS)}

Decision Support System (DSS) merupakan sistem informasi interaktif yang menyediakan informasi, permodelan dan pemanipulasian data. Sistem ini digunakan untuk membantu pengambilan keputusan dalam situasi yang semi terstrukstur dan situasi yang tidak terstruktur, dimana tak seorang pun tahu secara pasti bagaimana keputusan seharusnya dibuat [1][2].Aplikasi SMS interaktif

Aplikasi SMS interaktif merupakan sebuah program yang digunakan untuk melakukan komunikasi dua arah dengan memanfaatkan layanan SMS ( Short Message Service) agar program tersebut dapat membantu memudahkan seseorang dalam melaksanakan sebuah pekerjaan.

\section{B. Anlytical Hierarchy Process (AHP)}

Metode AHP ini merupakan suatu model pengambilan keputusan yang konpherensif dengan memperhitungkan halhal yang bersifat kualitatif dan kuantitatif. Dalam model pengambilan keputusan dengan AHP pada dasarnya berusaha menutupi semua kekurangn dari model-model sebelumnya. Berbagai penelitian yang menetapkan AHP diantaranya untuk memilih vendor baik skala industry kecil, menengah dan besar, menentukan sisa hasil usaha, penilaian pejabat struktural dan masih banyak lagi penerapan AHP yang menunjang proses pengambilan keputusan [3][4][5][6][7][8]. 
Dalam metode AHP dilakukan langkah-langkah sebagai berikut ( Kadarsyah Suryadi dan Ali Rhamdani, 1998) :

1. Mendefinisikan masalah dan menentukan solisi yang diinginkan

2. Membuat struktur hierarki yang diawali dengan tujuan utama

3. Membuat matrik perbandingan berpasangan yang menggambarkan konstribusi relative dan pengaruh setiap elemen terhadap tujuan atau kriteria yang setingkat diatasnya

4. Melakukan mendefinisikan perbandingan berpasangan sehingga diperoleh jumlah penilaian seluruhnya sebanyak $n$ x [(n-1/2)] buah, dengan $n$ adalah banyaknya elemen yang dibandingkan

5. Menghitung nilai eigen dan menguji konsistensinya

6. Mengulangi langkah 3,4 dan 5 untuk seluruh tingkat hirarki

7. Menghitung vector eigen dari setiap matriks perbandingan berpasangan yang merupakan bobot setiap elemen untuk penentian prioritas elemenelemen pada tingkat hirarki terendah sampai mencapai tujuan

8. Memeriksa konsistensi hirarki.

\section{METODOLOGI PENELITIAN}

Penelitian dilakukan dengan beberapa tahap guna mendapatkan data dan informasi yang akurat, diantaranya :

1. Tahapan Pengumpulan Data

Pada tahap ini dilakukan pengumpulan data dan informasi dari berbagai sumber.

2. Tahapan Analisa Data

Pada tahapan ini dilakukan beberapa tahapan diantaranya mendefinisikan masalah dan menganalisis data dengan menerapkan metode AHP sebagai mekanisme dalam sistem pendulung keputusan.

\section{HASIL DAN PEMBAHASAN.}

A. Analisis Kebutuhan Sistem.

a. Analisis Input

Proses pemilihan rumah kostt ini menggunakan empat kriteria sebagai masukan sistem, diantaranya jarak, harga, ukuran dan bangunan.

b. Analisis Output

Keluaran sistem yang dihasilkan adalah hasil perhitungan dengan menggunakan metode AHP dengan kriteria jarak, harga, ukuran dan bangunan.

c. Analisis Uji Coba

Alternatif yang digunakan dalam pemilihan rumah kostt adalah rumah kostt yang berada paling dekat dengan kampus yaitu rumah kostt milik H. Kirno, Romi, Yoko dan Suryaman.

\section{B. Analisis Menggunakan Metode AHP}

Analisa Sistem Pendukung Keputusan Pemilihan Rumah kost di Sekitar Kampus Unsera dengan menggunakan AHP melalui beberapa tahap berikut:

Mendefinisikan masalah dan menentukan solusi yang diinginkan

Penelitian ini berhasil mendefinisikan permasalahan diantaranya adalah banyaknya rumah kostt yang terletak strategis di dekat kampus dan seringnya terjadi pemilihan rumah kostt yang tidak tepat sehingga mengakibatkan mahasiswa berpindah-pindah rumah kostt sehingga mengakibatkan ketidakefektifan biaya, waktu dan tenaga. Solusi untuk mengatasi permasalaha ini adalah dengan menerapkan metode AHP untuk mendapatkan keputusan yang tepat dalam proses pemilihan rumah kostt.

Membuat struktur hierarki yang diawali dengan tujuan utama

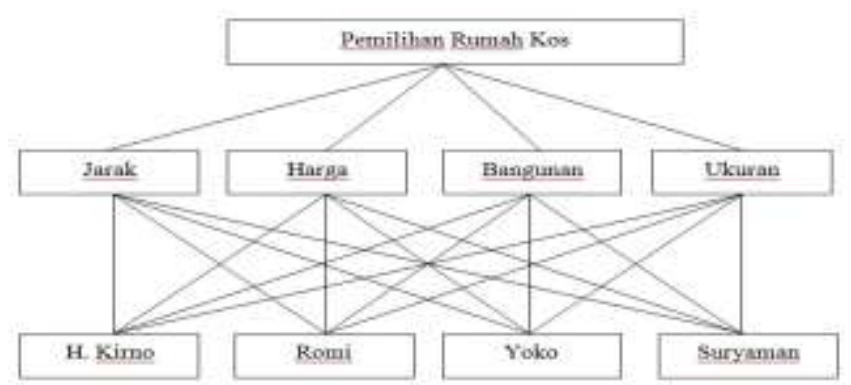

Gambar 1. Hirarki SPK Pemilihan rumah kostt

a. Membuat Matrik Perbandingan Berpasangan

Tabel 1.

Matrik Perbandingan Berpasangan

\begin{tabular}{|l|c|c|c|c|}
\hline Kriteria & Jarak & Harga & Bangunan & Ukuran \\
\hline Jarak & 1.00 & 3 & 5 & 7 \\
\hline Harga & 0.33 & 1.00 & 3 & 5 \\
\hline Bangunan & 0.20 & 0.33 & 1.00 & 3 \\
\hline Ukuran & 0.14 & 0.20 & 0.33 & 1.00 \\
\hline Jumlah & 1.68 & 4.53 & 9.33 & 16.00 \\
\hline
\end{tabular}

b. Melakukan mendefinisikan perbandingan berpasangan sehingga diperoleh jumlah penilaian seluruhnya sebanyak $\mathrm{n} \times[(\mathrm{n}-1 / 4]$ buah, dengan $\mathrm{n}$ adalah banyaknya elemen yang dibandingkan.

c. Tahapan selanjutnya adalah membuat matrik perbandingan untuk masing-masing kriteria, hasilnya sebagai berikut : 
d. Pair-wire comparation matrik untuk kriteria Jarak

Tabel 2. Tabel Pair-wire comparation matrik untuk kriteria Jarak

e.

\begin{tabular}{|l|c|c|c|c|}
\hline Jarak & H. Kirno & Romi & Yoko & Suryaman \\
\hline H. Kirno & 1,00 & 4 & 3 & 3 \\
\hline Romi & 0,25 & 1,00 & 3 & 2 \\
\hline Yoko & 0,33 & 0,33 & 1,00 & 2 \\
\hline Suryaman & 0,33 & 0,50 & 0,50 & 1,00 \\
\hline Jumlah & 1,92 & 5,83 & 7,50 & 8,00 \\
\hline
\end{tabular}

2) Pair-wire comparation matrik untuk kriteria Harga

Tabel 3. Tabel Pair-wire comparation matrik untuk kriteria Harga

\begin{tabular}{|l|c|c|c|c|}
\hline Harga & H. Kirno & Romi & Yoko & Suryaman \\
\hline H. Kirno & 1,00 & 3 & 2 & 3 \\
\hline Romi & 0,33 & 1,00 & 3,00 & 2 \\
\hline Yoko & 0,50 & 0,33 & 1,00 & 2 \\
\hline Suryaman & 0,33 & 0,50 & 0,50 & 1,00 \\
\hline Jumlah & 2,17 & 4,83 & 6,50 & 8,00 \\
\hline
\end{tabular}

3) Pair-wire comparation matrik untuk kriteria Bangunan

Tabel 4. Tabel Pair-wire comparation matrik untuk kriteria Bangunan

\begin{tabular}{|l|c|c|c|c|}
\hline Bangunan & H. Kirno & Romi & Yoko & Suryaman \\
\hline H. Kirno & 1,00 & 3 & 2 & 3 \\
\hline Romi & 0,33 & 1,00 & 4 & 3 \\
\hline Yoko & 0,50 & 0,25 & 1,00 & 3 \\
\hline Suryaman & 0,33 & 0,33 & 0,33 & 1,00 \\
\hline Jumlah & 2,17 & 4,58 & 7,33 & 10,00 \\
\hline
\end{tabular}

4) Pair-wire comparation matrik untuk kriteria Ukuran

Tabel 5. Tabel Pair-wire comparation matrik untuk kriteria Ukuran

\begin{tabular}{|l|c|c|c|c|}
\hline Ukuran & H. Kirno & Romi & Yoko & Suryaman \\
\hline H. Kirno & 1,00 & 3 & 2 & 5 \\
\hline Romi & 0,33 & 1,00 & 5 & 3 \\
\hline Yoko & 0,50 & 0,20 & 1,00 & 3 \\
\hline Suryaman & 0,20 & 0,33 & 0,33 & 1,00 \\
\hline Jumlah & 2,03 & 4,53 & 8,33 & 12,00 \\
\hline
\end{tabular}

e. Menghitung nilai eigen vector dan menguji konsistensinya matrik perbandingan berpasangan.

1) Menghitung nilai Eigen Vektor matrik perbandingan untuk masing-masing kriteria, hasilnya sebagai berikut :

Tabel 6. Nilai Eigen Vector dan Menguji Konsistensinya Matrik Perbandingan Berpasangan

\begin{tabular}{|c|c|c|c|c|c|}
\hline Kriteria & Jarak & Harga & Bangunan & Ukuran & $\begin{array}{l}\text { Eigen } \\
\text { Vektor }\end{array}$ \\
\hline Jarak & 1.00 & 3 & 5 & 7 & 0.56 \\
\hline Harga & 0.33 & 1.00 & 3 & 5 & 0.26 \\
\hline Bangunan & 0.20 & 0.33 & 1.00 & 3 & 0.12 \\
\hline Ukuran & 0.14 & 0.20 & 0.33 & 1.00 & 0.06 \\
\hline Jumlah & 1.68 & 4.53 & 9.33 & 16.00 & 1.00 \\
\hline \multicolumn{5}{|c|}{ Pricipal Eigen Value $\left(\%_{\max }\right)$} & 4.18 \\
\hline \multicolumn{5}{|c|}{ Consistensi Index $\left(\%_{\max }-n\right)(n-1)$} & 0.06 \\
\hline \multicolumn{5}{|c|}{ Consistensi Ratio CR (CI/IR) } & 0.07 \\
\hline
\end{tabular}

1) Menghitung nilai Eigen Vektor matrik perbandingan untuk masing-masing kriteria, hasilnya sebagai berikut :

a. Matrik Perbandingan Kriteria Jarak

Tabel 7. Tabel Matrik Perbandingan Kriteria Jarak

\begin{tabular}{|c|c|c|c|c|c|}
\hline Jarak & H. Kirno & Romi & Yoko & Suryaman & $\begin{array}{l}\text { Eigen } \\
\text { Vektor }\end{array}$ \\
\hline H. Kirno & 1,00 & 4 & 3 & 3 & 0,50 \\
\hline Romi & 0,25 & 1,00 & 3 & 2 & 0,24 \\
\hline Yoko & 0,33 & 0,33 & 1,00 & 2 & 0,15 \\
\hline Suryaman & 0,33 & 0,50 & 0,50 & 1,00 & 0,11 \\
\hline Jumlah & 1,92 & 5,83 & 7,50 & 8,00 & 1,00 \\
\hline \multicolumn{5}{|c|}{ Pricipal Eigen Value $\left(1_{\max }\right)$} & 4,38 \\
\hline \multicolumn{5}{|c|}{ Consistensi Index CI $\left(l_{\max }-n\right)(/ n-1)$} & 0,13 \\
\hline \multicolumn{5}{|c|}{ Consistensi Ratio CR (CI/IR) } & 0,14 \\
\hline
\end{tabular}


b) Matrik Perbandingan Kriteria Harga

Tabel 8. Tabel Matrik Perbandingan Kriteria Harga

\begin{tabular}{|l|c|c|c|c|c|}
\hline Harga & $\begin{array}{l}\text { H. } \\
\text { Kirno }\end{array}$ & Romi & Yoko & Suryaman & $\begin{array}{l}\text { Eigen } \\
\text { Vektot }\end{array}$ \\
\hline H. Kirno & 1,00 & 3,00 & 2,00 & 3,00 & 0,44 \\
\hline Romi & 0,33 & 1,00 & 3,00 & 2,00 & 0,27 \\
\hline Yoko & 0,50 & 0,33 & 1,00 & 2,00 & 0,18 \\
\hline Suryaman & 0,33 & 0,50 & 0,50 & 1,00 & 0,11 \\
\hline Jumlah & 2,17 & 4,83 & 6,50 & 8,00 & 1,00 \\
\hline Pricipal Eigen Value $\left(1_{\max }\right)$ & & 4,31 \\
\hline \multicolumn{7}{|l|}{ Consistensi Index CI (1 $\left.1_{\max }-\mathrm{n}\right)(/ \mathrm{n}-1)$} \\
\hline
\end{tabular}

c. Matrik Perbandingan Kriteria Bangunan

Tabel 9. Tabel Matrik Perbandingan Kriteria Bangunan

\begin{tabular}{|l|c|c|c|c|c|}
\hline Bangunan & $\begin{array}{l}\text { H. } \\
\text { Kirno }\end{array}$ & Romi & Yoko & Suryaman & $\begin{array}{l}\text { Eigen } \\
\text { Vektor }\end{array}$ \\
\hline H. Kirno & 1,00 & 3,00 & 2,00 & 3,00 & 0,42 \\
\hline Romi & 0,33 & 1,00 & 4,00 & 3,00 & 0,30 \\
\hline Yoko & 0,50 & 0,25 & 1,00 & 3,00 & 0,18 \\
\hline Suryaman & 0,33 & 0,33 & 0,33 & 1,00 & 0,09 \\
\hline Jumlah & 2,17 & 4,58 & 7,33 & 10,00 & 1,00 \\
\hline Pricipal Eigen Value $\left(1_{\max }\right)$ & & 4,56 \\
\hline \multicolumn{7}{|l|}{ Consistensi Index CI (1 $\left.1_{\max }-n\right)(/ n-1)$} & 0,19 \\
\hline
\end{tabular}

d. Matrik Perbandingan Kriteria Ukuran

Tabel 10. Tabel Matrik Perbandingan Kriteria Ukuran

\begin{tabular}{|l|c|c|c|c|c|}
\hline Ukuran & $\begin{array}{l}\text { H. } \\
\text { Kirno }\end{array}$ & Romi & Yoko & Suryaman & \\
\hline H. Kirno & 1,00 & 3,00 & 2,00 & 5,00 & 0,45 \\
\hline Romi & 0,33 & 1,00 & 5,00 & 3,00 & 0,31 \\
\hline Yoko & 0,50 & 0,20 & 1,00 & 3,00 & 0,17 \\
\hline Suryaman & 0,20 & 0,33 & 0,33 & 1,00 & 0,07 \\
\hline Jumlah & 2,03 & 4,53 & 8,33 & 12,00 & 1,00 \\
\hline Pricipal Eigen Value $\left(1_{\max }\right)$ & & 4,58 \\
\hline Consistensi Index CI (1 $\left.1_{\max }-\mathrm{n}\right)(/ \mathrm{n}-1)$ & 0,19 \\
\hline
\end{tabular}

a. Menghitung nilai total keseluruhan hasil matrik perbandingan berpasangan atau Overall composite weight, seperti tabel berikut :
Tabel 11. Tabel Tabel Nilai Total Keseluruhan Hasil Matrik

\begin{tabular}{|l|c|c|c|c|c|}
\hline \multicolumn{1}{|c|}{ OCW } & Weight & $\begin{array}{c}\text { H. } \\
\text { Kirno }\end{array}$ & Romi & Yoko & Suryaman \\
\hline Jarak & 0,56 & 0,5 & 0,24 & 0,15 & 0,11 \\
\hline Harga & 0,26 & 0,44 & 0,27 & 0,18 & 0,11 \\
\hline Bangunan & 0,12 & 0,42 & 0,30 & 0,18 & 0,09 \\
\hline Ukuran & 0,06 & 0,45 & 0,31 & 0,17 & 0,01 \\
\hline $\begin{array}{l}\text { Composit } \\
\text { e Weight }\end{array}$ & & $\mathbf{0 , 4 7}$ & $\mathbf{0 , 2 6}$ & $\mathbf{0 , 1 6}$ & $\mathbf{0 , 1 0}$ \\
\hline
\end{tabular}

Dari hasil perhitungan diatas maka dapat disimpulkan bahwa H.Kirno memiliki nilai Composite Weigt 0,47, Romi memiliki nilai 0,26, Yoko memiliki nilai 0,16 dan Suryaman memiliki nilai 0,10 . Hasil akhirnya adalah rumah kostt milik $H$. Kirno menjadi prioritas utama dalam pemilihan rumah kostt yang ada disekitar lingkungan kampus Universitas Serang Raya (UNSERA).

\section{KESIMPULAN}

Penilitian ini menghasilkan analisis sistem pendukung keputusan untuk pemilihan rumah kostt di sekitar lingkungan kampus Universitas Serang Raya, yang dapat dijadikan rekomendasi bagi mahasiswa untuk menentukan pilihan yang tepat dalam hal memilih rumah kostt sesuai dengan keinginan

\section{DAFTAR PUSTAKA}

[1] Kusrini, Konsep dan Aplikasi Sistem Pendukung Keputusan, Penerbit Andi : Yogyakarta, 2007.

[2] Makassau Kasman, Penggunaan Analitycal Hierarchy Process (AHP) dalam penentuan prioritas program kesehatan (study kasus Program Promosi Kesehatan), J@TI Undip, Vol VII, No 2, Mei 2012

[3] Harsiti, Saefudin, Rosalina, Vidila, Prototype Sistem Pendukung Keputusan Penyelaksian Atlet Berprestasi Dengan Menggunakan Metode Analytical Hierarchy Process (AHP), Jurnal Sistem Informasi (JSII), ISSN : 2406-7768 Volume 1, Agustus 2014.

[4] Saefudin, Wahyuningsih Sri, Sistem Pendukung Keputusan untuk Penilaian Kinerja Pegawai Menggunakan Metode Analytical Hierarchy Process (AHP) Pada RSUD Serang, Jurnal Sistem Informasi (JSII), ISSN : 2406-7768 Volume 1, Agustus 2014.

[5] Amborowati Armadyah, Sistem Pendukung Keputusan Pemilihan Karyawan Berprestasi Berdasarkan Kinerja (Studi kasus pada STMIIK AMIKOM Yogyakarta).

[6] Arifin Zainal, Penerapan Metode Analytical Hierarchy Procces (AHP) Untuk Menentukan Sisa Hasil Usaha Koperasi Pegawai Negeri, Jurnal Informatika Mulawarman, Volume 5 No. 2 Juli 2010. 
[7] Londa Maria Adelvin, Sara Kristina, 2012, Sistem Penilaian Pejabat Struktural dengan Metode Analytical Hierarchy Procces (AHP) dan Linier Programming (Studi Kasus Analisis Evaluasi Kinerja Pejabat Struktural Universitas Flores), Seminar Nasional TEKNOIN 2012 ISBN 979-978-96964-9-8, Vol VII, No 2, Mei 2012.

[8] Muhammad Gilang R, Taufiq Timur Warisaji, Sistem Pendukung Keputusan untuk menentukian atlet lari jarak pendek dalam mengikuti seleksi Kabupaten Jember di KONI Kabupaten Jember menggunakan Metode Analytical Hierarchy Process, Skripsi/Tugas Akhir Universitas Muhammadiyah Jember., 2002.

http://teddyabout.web.ugm.ac.id/download/BAB\%20II.pdf

[10] Valzki (2005), "Sistem Informasi Jadwal Konsultasi Dokter Via Sms.” Abstraksi, Diakses 09 April 2008. 